\title{
COVID with Diabetic Ketoacidosis: Intriguer or Consequence
}

\author{
Yashaswini $\mathrm{K}^{1}$ - Lalitha A. $\mathbf{V}^{1}$ - Chandrakant G. Pujari ${ }^{1}$ (D) R. N. Poornima ${ }^{2}$
}

Received: 28 December 2020 / Accepted: 21 January 2021 /Published online: 7 April 2021

(C) Dr. K C Chaudhuri Foundation 2021

To the Editor: COVID-19 being a multisystem inflammatory state, it is theoretically possible that any of the organ systems with the angiotensin-converting enzyme 2 (ACE2) receptors in abundance might be a source of some clinical manifestation. Endocrine and exocrine dysfunction of pancreas may be one such manifestation. Here, we present a series of 5 children ( 3 female and 2 male) with diabetes ketoacidosis (DKA) with COVID-19 admitted to our center between May 2020 and August 2020.

COVID antigen testing was positive for 4 children while RT-PCR report was positive for 1 child. In the present case series, 4 children had severe DKA while 1 had moderate DKA; acute kidney injury was present in all children but only one patient required renal replacement therapy while others improved with medical management during treatment course. Cerebral edema was present in 3 patients and it was managed conservatively. None of them had any significant radiograph findings and did not require any supplemental oxygen support.

Lymphopenia was present in 1 patient (severe DKA), Serum ferritin was done in 2 patients and it was within normal limit, D-dimer was done in 3 patients and it was elevated in all 3 of them (severe DKA), C-reactive protein and procalcitonin was positive in one patient (severe DKA).

COVID-19 and DKA are both hyperinflammatory states, which, in conjunction, would theoretically result in hyperacute rapidly progressive illness [1]. The exact mechanism of such presentation in association with SARS CoV2 is still presumptive. ACE2 is highly expressed in the lungs and

Chandrakant G. Pujari

kantbmc@gmail.com

1 Department of Pediatric Critical Care, St Johns Medical College and Hospital, Bangalore 560034, India

2 Department of Pediatrics, St Johns Medical College and Hospital, Bangalore, India pancreas and entry of SARS-CoV-2 into pancreatic islet cells may directly aggravate beta cell injury $[2,3]$ and massive cytokine release can damage islet cells [4].

Though the exact causal and co-existence relationship between diabetic ketoacidosis and COVID-19 is still presumptive, it is wise to be watchful of its occurrence. This may serve as an opportunity to institute-appropriate COVID-19 screening measures in children presenting as DKA.

\section{Compliance with Ethical Standards}

Conflict of Interest None.

\section{References}

1. Singh AK, Gupta R, Ghosh A, Misra A. Diabetes in COVID-19: prevalence, pathophysiology, prognosis and practical considerations. Diabetes Metab Syndr. 2020;14(4):303-10.

2. Roca-Ho H, Riera M, Palau V, et al. Characterization of ACE and ACE2 expression within different organs of the NOD mouse. Int $\mathrm{J}$ Mol Sci. 2017;18:E563.

3. Carlsson PO, Berne C, Jansson L. Angiotensin II and the endocrine pancreas: effects on islet blood flow and insulin secretion in rats. Diabetologia. 1998;41(2):127-33.

4. Palermo NE, Sadhu AR, McDonnell ME. Diabetic ketoacidosis in COVID-19: unique concerns and considerations. J Clin Endocrinol Metab. 2020;105(8):1-11.

Publisher's Note Springer Nature remains neutral with regard to jurisdictional claims in published maps and institutional affiliations. 